\title{
Infrastructure Domestic and International
}

National Cancer Institute

\section{Source}

National Cancer Institute. Infrastructure Domestic and International. NCI Thesaurus. Code C18852.

Establish appropriate infrastructure for the conduct of HIV research domestically and internationally. 